\title{
Resistance of Wheat Line Kavkaz-K4500 L.6.A.4 to Septoria Tritici Blotch Controlled by Isolate-Specific Resistance Genes
}

\author{
L. Chartrain, S. T. Berry, and J. K. M. Brown
}

First author: Department of Disease and Stress Biology, John Innes Centre, Norwich Research Park, Norwich NR4 7UH, UK and ENSAT, Laboratoire de Biologie et Amélioration des Plantes, Avenue de l'Agrobiopole, BP 107, 31326 Castanet-Tolosan, France; second author: Advanta Seeds UK Ltd., Station Road, Docking, King's Lynn, Norfolk, PE31 8LS, UK; and third author: Department of Disease and Stress Biology, John Innes Centre, Norwich Research Park, Norwich NR4 7UH, UK.

Accepted for publication 20 January 2005

\begin{abstract}
Chartrain, L., Berry, S. T., and Brown, J. K. M. 2005. Resistance of wheat line Kavkaz-K4500 L.6.A.4 to Septoria tritici blotch controlled by isolate-specific resistance genes. Phytopathology 95:664-671.

The International Maize and Wheat Improvement Center (CIMMYT), Mexico, germplasm-derived wheat (Triticum aestivum) Kavkaz-K4500 L.6.A.4 (KK) is one of the major sources of resistance to Septoria tritici blotch (STB). KK is resistant to STB in field conditions in the UK even though a large majority of Mycosphaerella graminicola isolates are virulent to it. The genetics of the resistance of KK to four isolates of

M. graminicola were investigated. KK has at least five isolate-specific resistance genes including Stb6 on chromosome 3A plus a second gene for resistance to isolate IPO323, two genes on chromosome 4A, both in the region where $S t b 7$ is located with one designated as $S t b 12$, and a gene designated $S t b 10$ on chromosome 1D. Taken together, the widespread use of KK as a source of resistance to STB, its high resistance in field conditions, and its high susceptibility to $M$. graminicola isolates, which are virulent to all its resistance genes, suggest that high levels of field resistance to STB might be achieved by pyramiding several isolate-specific resistance genes.
\end{abstract}

Septoria tritici blotch (STB), caused by the ascomycete fungus Mycosphaerella graminicola, is currently the most important foliar disease of wheat (Triticum aestivum) in Europe and several other parts of the world $(16,18,24,39,44)$. The use of fungicides to control STB is expensive and not entirely reliable. Recently isolates of M. graminicola resistant to strobilurin (Qo inhibitor) fungicides have become common in Europe and there has been widespread failure of QoI fungicides to control STB (5). Breeding for resistance is an effective way of controlling STB, and resistance to STB is an important consideration when farmers in areas where the disease is prevalent are choosing wheat varieties.

The International Maize and Wheat Improvement Center (CIMMYT), Mexico, derived germplasm Kavkaz-K4500 L.6.A.4 (KK) was one of the first varieties identified as a source of resistance to STB. KK was bred from, among other varieties, the Russian winter wheat Kavkaz and the Brazilian cv. Frontana (17), both of which are themselves sources of resistance to STB. KK was first used in CIMMYT breeding programs in the 1970s (22). Several seedling and detached leaf studies showed that KK was resistant to many isolates of $M$. graminicola but susceptible to others $(17,19,30-32)$. Eyal et al. (19) suggested that resistance of KK to STB could be controlled by as many as seven genes, whereas Kema et al. (31) suggested that broad resistance of KK could be due to one resistance gene for which virulence in the pathogen population is rare. However, KK is susceptible to most of the UK population of M. graminicola (J. C. Makepeace, C. M. Raitt, R. A. Bayles, and J. K. M. Brown, unpublished data) despite being resistant in field conditions (10) and is very susceptible to virulent $M$. graminicola isolates in seedling tests (13).

The genetics of resistance to STB are less studied than those of powdery mildew or the rusts and are still unclear in some re-

Corresponding author: J. K. M. Brown; E-mail address: james.brown@bbsrc.ac.uk

DOI: 10.1094/PHYTO-95-0664

(C) 2005 The American Phytopathological Society spects. Resistance to STB may be either quantitative or specific. Quantitative resistance is incomplete, polygenic $(28,42,48)$, and isolate nonspecific (14), whereas specific resistance is near-complete, isolate-specific, and oligogenic (8) and follows a gene-forgene relationship (9). Several genes for resistance to STB have been identified, of which $S t b 1$ to $S t b 9$ have been identified using defined isolates of $M$. graminicola and have been mapped (1$4,8,9,11,35)$.

Along with high levels of resistance to STB in the field, KK is resistant as seedlings to specific $M$. graminicola isolates such as the Dutch isolates IPO323 and IPO94269 $(7,13,33)$, the Israeli isolates ISR398 and ISR8036 (47), and the Uruguayan isolate IPO87019 (13). Previously, the resistance of KK to IPO323 has been shown to be conferred by two genes, one of them being Stb6 on chromosome $3 \mathrm{~A}$ (12).

This paper reports an investigation of the genetics of the resistance of KK to four M. graminicola isolates, ISR398, ISR8036, IPO87019, and IPO94269. It is shown that the resistance of KK to these isolates is controlled by a combination of genes including two genes on chromosome 4A, one of which may be $S t b 7$ and the other is named Stb12, and a third gene named Stb10 on chromosome 1D.

\section{MATERIALS AND METHODS}

Isolates. The five STB isolates used in this study were provided by G. H. J. Kema, Plant Research International, The Netherlands (IPO isolates) and S. Ezrati, Tel Aviv University, Israel (ISR isolates). IPO87019, IPO94269, IPO92006, ISR398, and ISR8036 were chosen for their avirulence on KK and IPO92006 was a virulent control $(6,13,15,31,33)$. All isolates were grown on potato dextrose agar for 7 to 10 days before inoculation. The inoculum concentration was adjusted to $10^{7}$ conidia $\mathrm{ml}^{-1}$.

Plant material. The work reported here used an F5 plantderived F6 single seed descent (SSD) population of a cross between KK and susceptible cv. Shafir, provided by the late R. Rai, 
Cebeco B.V., The Netherlands, and the late I. L. Groenewegen, Wiersum-Zelder B.V., The Netherlands.

Pathology tests. Pathology tests were done on whole seedlings and detached leaves. Whole seedling tests allow a greater number of plants to be tested compared with the detached leaf method, but with the disadvantage that environmental conditions are less strictly controlled. For specific resistances, tests on whole seedlings and detached leaves provided similar results (7). Only detached leaves were used for isolates IPO94269 and IPO87019 because they were not sufficiently aggressive to be tested on whole seedlings. Isolate ISR8036 was tested on whole seedlings. ISR398 was tested once on whole seedlings and once on detached leaves. Eight detached leaves per line were used for the virulent control isolate IPO92006.

Seedling tests in the glasshouse were done by the method of Brading et al. (9) with minor modifications. Eighteen seedlings per line were tested with both parents and the susceptible cv. Longbow as controls. Each tray of 14- to 16-day-old seedlings was sprayed with $50 \mathrm{ml}$ of spore suspension. To keep the first leaf alive so that symptoms could be scored, upper leaves were cut off each week (9). Trays were moved weekly to avoid possible position effects.

Detached leaf tests were performed according to the method of Arraiano et al. (7) with minor modifications. In each test, for each line, four replicate leaf sections from different seedlings were tested and 'Longbow' was used as a susceptible control.

Disease scoring. In both detached leaf and whole seedling tests, the disease was scored as the percentage of leaf area covered by lesions bearing pycnidia. In whole seedling tests, the primary leaf of each plant was scored once when several leaves were severely diseased ( $90 \%$ or more of lesions bearing pycnidia). This was 20 days postinoculation (dpi) with ISR8036 but 29 dpi with ISR398, due to the different aggressiveness of the isolates (13). Disease scores were logit-transformed and the mean disease logit-scores and the standard deviations were calculated for each line.

In detached leaf tests, leaves were scored four to five times between 2 and 4 weeks postinoculation, and the area under disease progress curve (AUDPC) (41) was calculated. The variate analyzed was the AUDPC as a proportion of the maximum possible AUDPC (maxAUDPC, calculated assuming a score of $100 \%$ on every date the test was scored). The mean AUDPC was calculated for each line by generalized linear mixed modeling (GLMM) using the statistics program Genstat 5 for Windows, 6th edition (37).

DNA extraction. DNA from the Shafir $\times$ KK F5 SSD population was extracted from several 2-week-old seedlings of each line, using a GenomicPrep kit (Amersham Biosciences, Amersham, UK) with some modifications from the original manufacturer's instructions.

Molecular mapping. Polymerase chain reaction (PCR) tests used $2 \mu \mathrm{l}$ of DNA template and $0.3 \mu \mathrm{l}$ of $50 \mathrm{mM} \mathrm{MgCl}_{2}, 1 \mu \mathrm{l}$ of 10× PCR buffer (Invitrogen, Paisley, UK), $0.2 \mathrm{mM}$ each of $5 \mathrm{mM}$ dNTPs, 0.5 units of Platinum Taq DNA polymerase (Invitrogen), and IRD-labeled forward (Biolegio, Holland) and reverse primers at concentrations varying from 0.05 to $0.25 \mathrm{pmol}$, depending on the primer used. Water was added to a final reaction volume of $10 \mu \mathrm{l}$. The microsatellite loci were amplified using an annealing temperature of 50 or $60^{\circ} \mathrm{C}$ depending on the marker, and the PCR program used was as described by Röder et al. (40), with the exceptions that all the times were reduced by half and the total number of cycles was only 35 . The PCR products were pooled, diluted with loading buffer, denatured, and run on $6.5 \%$ acrylamide gel using a DNA sequencer (Li-Cor 4200; Li-Cor, Cambridge, UK).

Bulk segregant analysis (BSA) (36) was used to identify chromosomes on which resistance genes may be located. For resistance to ISR398 and IPO94269, each bulk contained DNA from eight clearly resistant or susceptible lines. One resistant bulk and one susceptible bulk for each of the M. graminicola isolates ISR398 and IPO94269 and both parents were screened with a total of 181 microsatellite markers selected to give good genome coverage. The simple sequence repeats were sourced from the Wheat Microsatellite Consortium (WMC) (markers developed by an international consortium led by Agrogene S.A., Moissy Cramayel, France) as well as those described by Röder et al. (40) and Pestsova et al. (38). Two markers, WMS603 and WMS848, belonging to the Institute for Plant Genetics and Crop Plant Research and Trait Genetics GmbH were also used. (These are proprietary markers but are available for academic research purposes. Requests for the primer sequences should be directed to M. Ganal at Trait Genetics GmbH, Am Schwabeplan 1b, D-06466 Gatersleben, Germany.) Selected markers of interest were then screened against the entire F5 SSD population.

Linkage analysis was done using JoinMap version 2.0 (43). Recombination fractions were converted into centimorgan distances using the Kosambi map function (34). Quantitative trait loci (QTL) analysis was done by interval mapping (26) or by multiple QTL mapping (MQM) when more than one QTL was predicted $(26,27)$ using MapQTL version 4.0 (45). Interaction between the different resistance genes was assessed by analysis of variance (ANOVA) using Genstat 5.

\section{RESULTS}

Pathology tests. All lines were susceptible to IPO92006 with at least $63 \%$ disease.

Test on whole seedlings with ISR398 showed two fairly distinct groups (Figs. 1A and 2A). Of the 99 lines tested, 64 had mean disease scores of $13 \%$ or less, and 35 lines had mean scores of $35 \%$ or more. High standard deviation of the logit scores for several lines suggested that they segregated for resistance to ISR398. In an F5 SSD population, 6\% of lines are expected to segregate at any one locus but particular segregating lines could not be identified with confidence in this test. Mean disease scores from the detached leaf test with ISR398 were highly correlated with those from the seedling test $(r=0.87 ; P \leq 0.001)$. As in the test on whole seedlings, it was not possible to identify clearly segregating lines.

In order to identify lines segregating for responses to IPO87019, 12 leaves per line were tested. Resistant lines with low scores and low standard deviation of the scores could be distinguished from susceptible lines with high scores and low standard deviation (Fig. 1B), except for two lines (Fig. 2B).

Detached leaf tests with IPO94269 were performed twice with eight seedlings per line in total (Fig. 1C). The ratio between the mean AUDPC with IPO92469 and the mean AUDPC with IPO92006 was calculated as a measure of specific resistance to IPO94269 (Fig. 2C). A simple segregation ratio could not be determined, indicating either that resistance to IPO94269 is less clearly expressed than that to ISR398 or that resistance might be controlled by more than one gene. Disease levels with IPO94269 were low compared with those of the other isolates tested due to its low aggressiveness. Several lines with very low mean scores and low standard deviation of scores were classified as resistant, while several lines with mean scores similar to or higher than those of Shafir and with low standard deviation of scores were classified as susceptible (Fig. 1C).

Ninety four lines were tested with ISR8036 in whole seedling tests. As with the other isolates, several lines were clearly resistant, with low mean scores and low standard deviation, and several lines were clearly susceptible with high mean scores, but it was not possible to classify the lines into clear resistant and susceptible groups (Figs. 1D and 2D).

Principal component analysis and correlations between isolates. Principal component analysis (PCA) was used to detect similarities in the lines' responses to the four isolates. The 
measure of isolate-specific resistance was the logit mean score with the avirulent isolate minus the logit mean with IPO92006. The first three components explained almost $100 \%$ of the total variation (Table 1). Principal component (PC) 1 contrasted responses to ISR398 and IPO87019 with those to ISR8036 and IPO94269. This implies that specific resistances to ISR398 and IPO87019 are associated, as are the specific resistances to ISR8036 and IPO94269. These associations could be due to the resistance genes being the same or being located on the same chromosome. PC2 distinguished responses to IPO94269 from those to ISR8036, suggesting that there is another component of resistance effective against ISR8036, but not against IPO94269. PC3 contrasted responses to ISR398 and IPO87019, indicating that there were as least a few lines in which specific resistance to these two isolates segregated from one another.

There were positive correlations between disease caused by all isolates, showing that there is an isolate nonspecific component of resistance that is effective against all isolates including IPO92006
(Table 2). Partial correlation analysis showed strong positive correlations between responses to IPO87019 and ISR398 and between those to IPO94269 and ISR8036 (Table 2; Fig. 3), which confirmed the results obtained by PCA (Table 2). Responses to ISR398 and ISR8036 were also moderately correlated. There was no partial correlation between any avirulent isolate and the virulent control IPO92006, indicating that none of the specific resistance genes segregating in this populations affected responses to IPO92006.

Four lines were specifically resistant to ISR398 but susceptible to IPO87019 (Fig. 4), indicating that there is a gene that controls resistance to ISR398, but not to IPO87019. Three other lines may also be resistant to ISR398 and susceptible to IPO87019 and one line may be resistant to IPO87019 but susceptible to ISR398 (Fig. 4), so the recombination fraction between the two genes appears to be between 0.04 and 0.08 .

Molecular mapping. Of 181 markers tested in the BSA, one, $X w m c 219$ on the distal end of the long arm of chromosome 4A, amplified the KK allele in the ISR398-resistant bulk and the
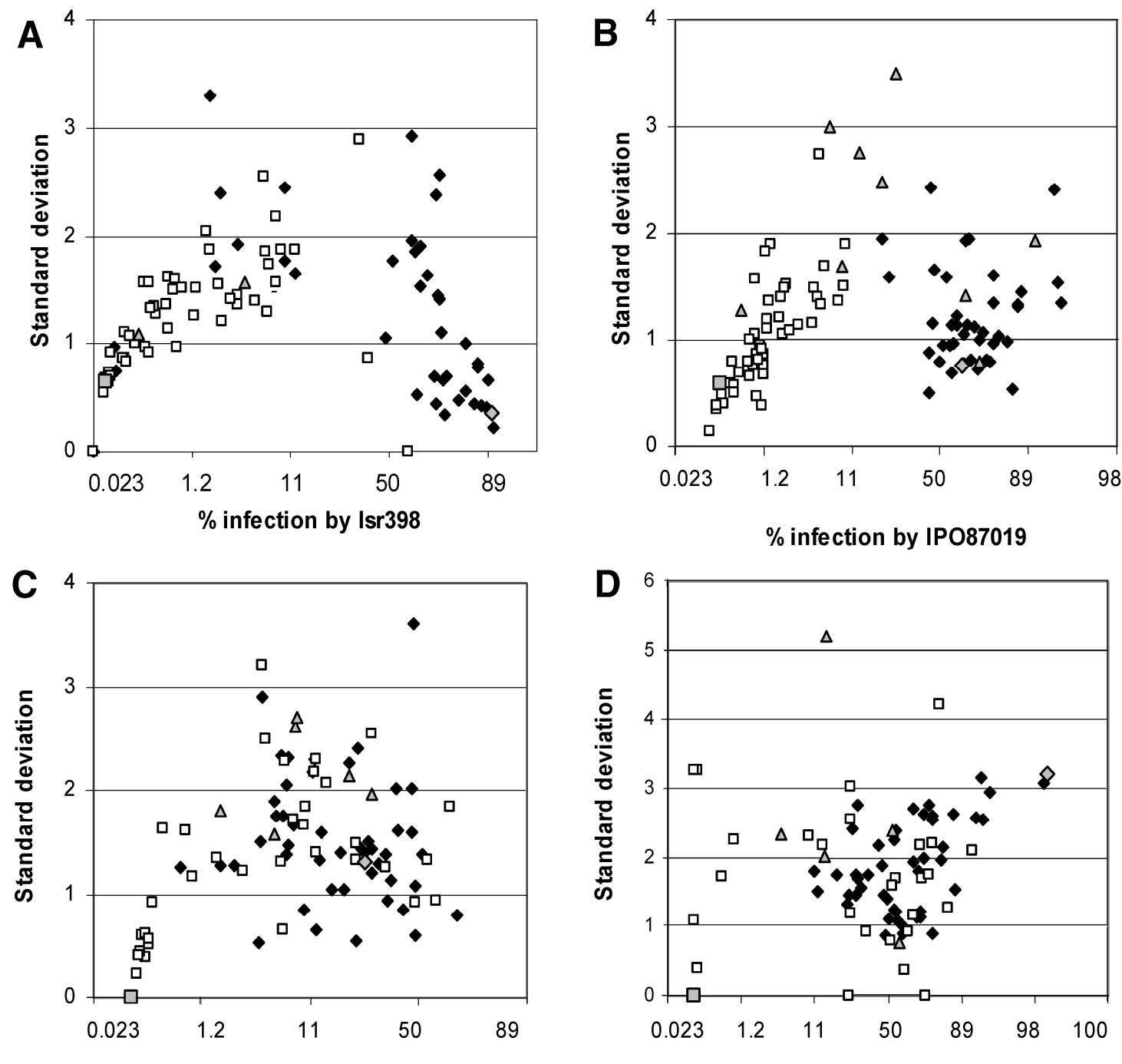

$\%$ infection by IPO94269

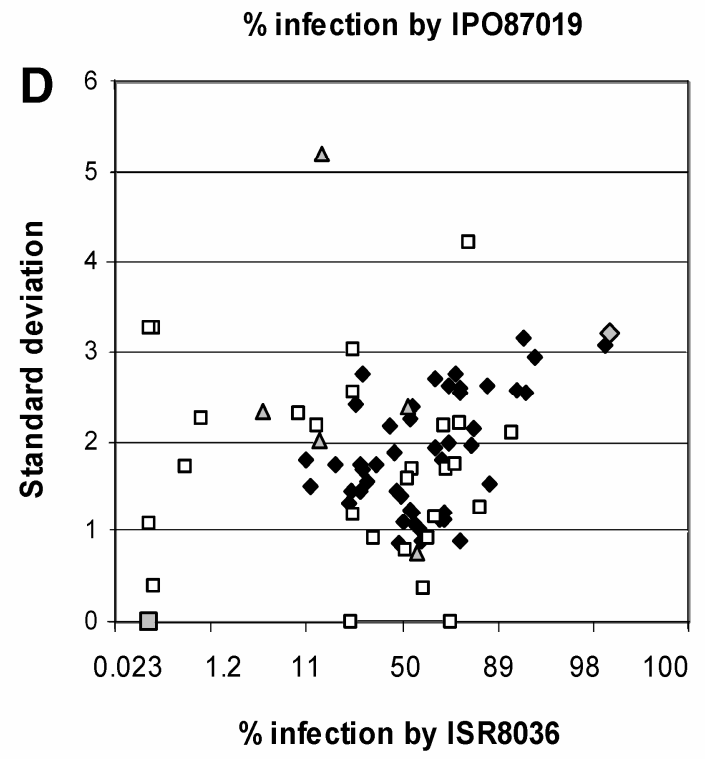

KK $\quad$ KKallele $\square \quad$ Shafir allele $\bullet$ Heterozygote $\Delta \quad$ Shafir $\diamond$

Fig. 1. Segregation of responses of Shafir $\times$ Kavkaz-K4500 L.6.A.4 (KK) F5 single seed descent lines to four isolates of Mycosphaerella graminicola. Standard deviation of logit disease scores are plotted against mean disease scores for each line. Disease is shown as area under disease progress curve (AUDPC) as a percentage of maximum possible AUDPC. For each isolate, lines are marked by their allele of the closest marker to the most important resistance gene. A, M. graminicola isolate ISR398, closest marker Xwmc219 on chromosome 4AL. B, Isolate IPO87019, closest marker Xwmc313 on chromosome 4AL. C, Isolate IPO94269, closest marker Xgwm 848 on the centromere of chromosome 1D. D, Isolate ISR8036, closest marker Xgwm 848 on the centromere of chromosome 1D. The axis showing the mean disease scores is logit-scaled. 
Shafir allele in the susceptible bulk. To generate a map of the region, nine markers located on chromosome 4A were mapped on the 99 F5 lines (Fig. 4A). Two other markers, Xgwm160 and $X w m c 313$, were closely linked to the resistance gene (Student's $t$ test, $P<0.001$ for both markers).

For resistance to IPO94269, bulks were screened with the same 181 microsatellite markers. Five markers amplified the KK allele in the IPO94269-resistant bulk and the Shafir allele in the susceptible bulk: Xgwm848 on chromosome 1D, Xwmc235 and Xgwm604 on chromosome 5B, Xgwm814 on chromosome 6B, and Xgwm681 on chromosome 7A. Each of these markers was mapped on the F5 SSD population and logit AUDPC means of the lines with the KK allele were compared with those of the Shafir allele for each marker. Disease scores were significantly associated with $X g w m 848$ (Student's $t$ test, $P<0.001$ ), but not with any of the other markers. Four microsatellite markers mapping on chromosome 1D were mapped on 99 SSD lines and used to generate a map of the region of interest.
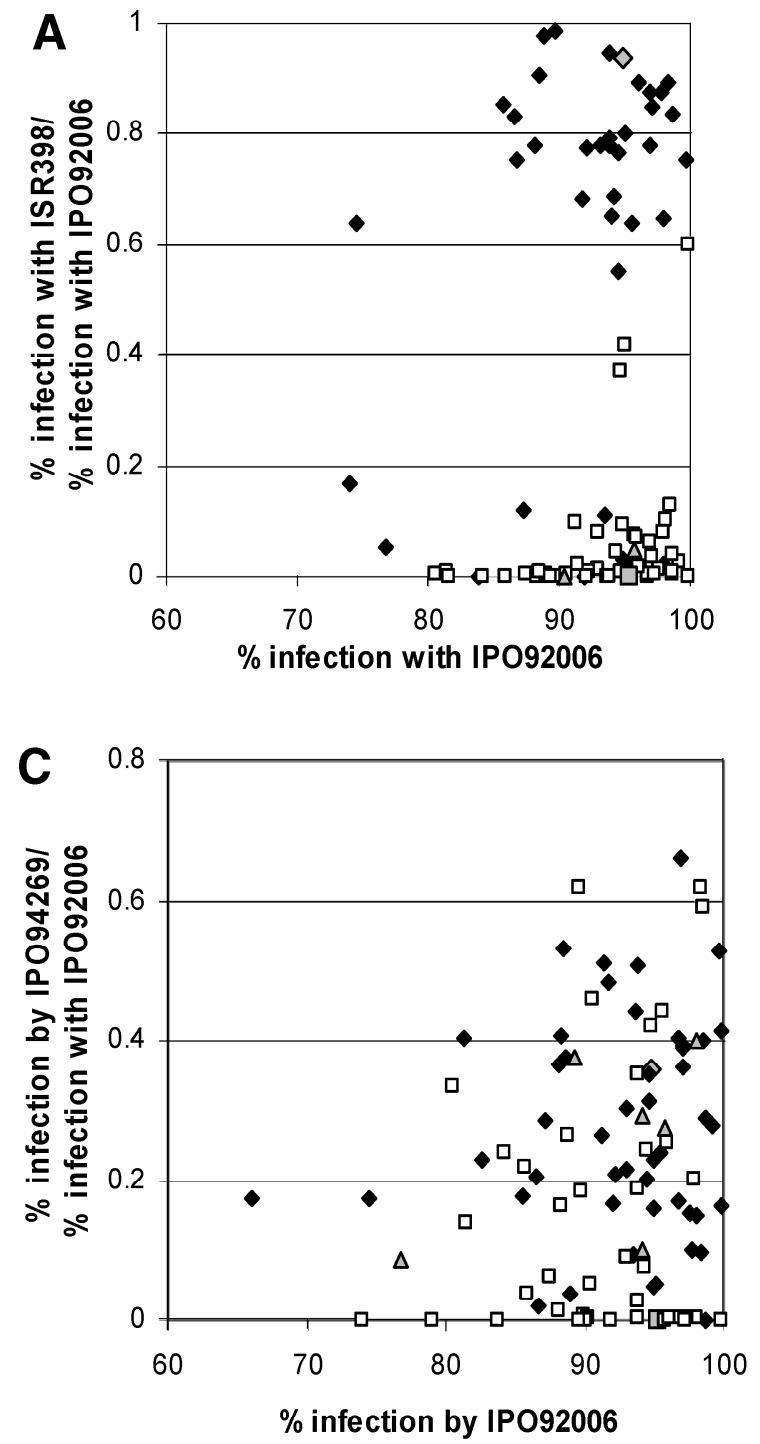

With all the isolates, several lines had intermediate disease levels in pathology tests and could not be classified as resistant or susceptible. Genes for resistance to these isolates were therefore mapped by QTL analysis. All traits were tested on the two maps

TABLE 1. Principal component analysis of logit mean levels of Septoria tritici blotch caused by Kavkaz-K4500 L.6.A.4 (KK)-avirulent isolates of Mycosphaerella graminicola on progeny lines of Shafir $\times \mathrm{KK}$

\begin{tabular}{lcrrr}
\hline & \multicolumn{4}{c}{ Principal component } \\
\cline { 2 - 5 } & 1 & \multicolumn{1}{c}{2} & 3 & 4 \\
\hline \% Variation & 52 & 28 & 18 & 2 \\
Loading of isolates & & & & \\
ISR398 & 0.51 & 0.02 & 0.78 & 0.35 \\
IPO87019 & 0.58 & -0.08 & -0.62 & 0.52 \\
IPO94269 & -0.32 & 0.83 & -0.02 & 0.46 \\
ISR8036 & -0.55 & -0.55 & 0.09 & 0.62 \\
\hline
\end{tabular}
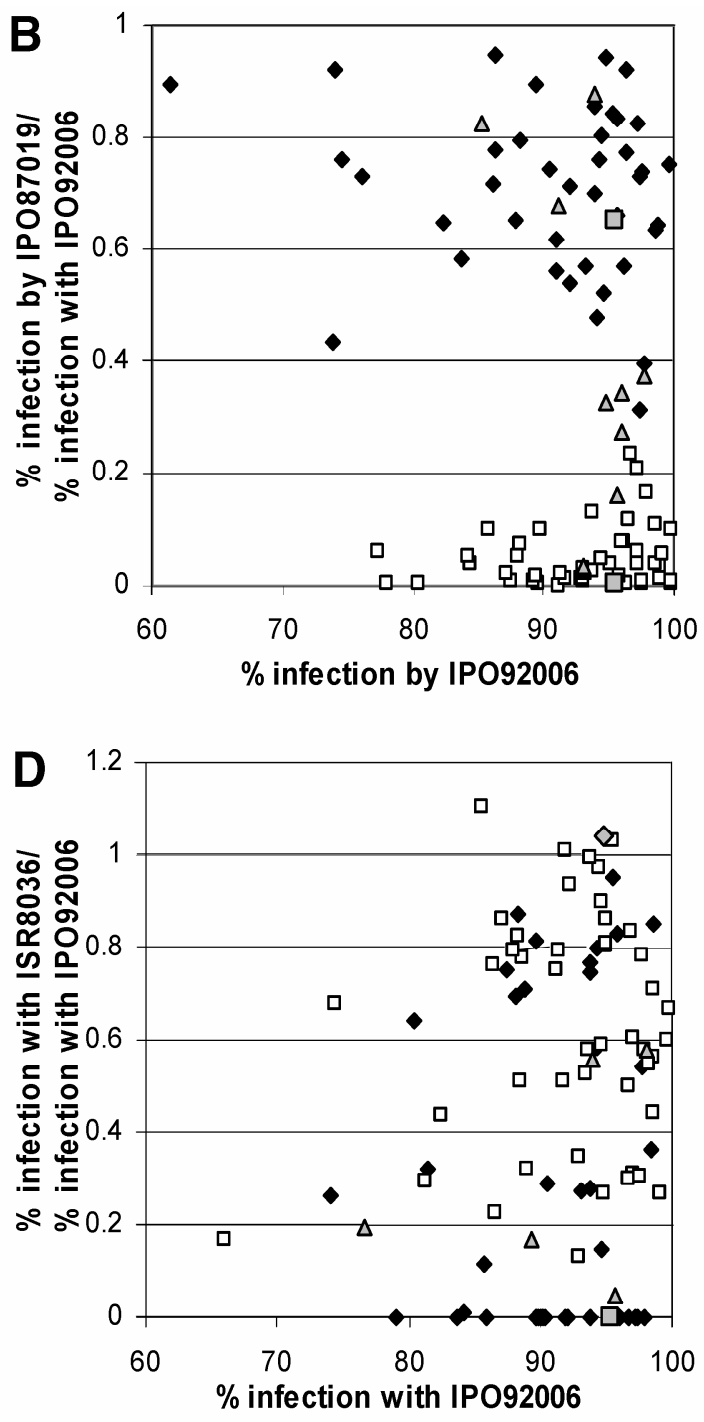

KK $\quad$ KKallele $\square \quad$ Shafir allele $\bullet$ Heterozygote $\Delta \quad$ Shafir $\diamond$

Fig. 2. Segregation of Shafir $\times$ Kavkaz-K4500 L.6.A.4 (KK) F5 single seed descent lines for specific resistance to Mycosphaerella graminicola isolates. The ratio of the mean area under disease progress curve (AUDPC) for each line inoculated with isolates avirulent on KK (A, ISR398; B, IPO87019, C, IPO94269; and D, ISR80360) to mean AUDPC with the virulent control isolate IPO92006, a measure of specific resistance to the avirulent isolate, is plotted against mean AUDPC with IPO92006 only. Mean AUDPC is shown as a percentage of the maximum possible AUDPC. For each isolate, lines are marked by their allele of the closest marker to the most important resistance gene. A, M. graminicola isolate ISR398, closest marker Xwmc219 on chromosome 4AL. B, Isolate IPO87019, closest marker Xwmc313 on chromosome 4AL. C, Isolate IPO94269, closest marker Xgwm848 on the centromere of chromosome 1D. D, Isolate ISR8036, closest marker Xgwm848 on the centromere of chromosome 1D. The axis showing the mean disease scores is logit-scaled. 
of chromosomes 1D and 4A by interval mapping or by MQM when more than one QTL was suspected.

Interval mapping showed that one major QTL for resistance to ISR398 (LOD $=16.18$ ), explaining $54 \%$ of the genotypic variance, mapped close to Xwmc 219 on chromosome $4 \mathrm{~A}$, indicating the existence of a gene for resistance to this isolate on the

TABLE 2. Correlation between logit mean levels of Septoria tritici blotch caused by five isolates of Mycosphaerella graminicola on progeny lines of Shafir $\times$ Kavkaz-K4500 L.6.A.4

\begin{tabular}{lccccc}
\hline & ISR398 & IPO87019 & IPO94269 & ISR8036 & IPO92006 \\
\hline Correlations & & & & & \\
ISR398 & 1.00 & $\ldots$ & $\ldots$ & $\ldots$ & $\ldots$ \\
IPO87019 & 0.74 & 1.00 & $\ldots$ & $\ldots$ & $\ldots$ \\
IPO94269 & 0.39 & 0.13 & 1.00 & $\ldots$ & $\ldots$ \\
ISR8036 & 0.60 & 0.32 & 0.70 & 1.00 & $\ldots$ \\
IPO92006 & 0.14 & 0.01 & 0.15 & 0.14 & 1.00 \\
Partial correlations & & & & & \\
ISR398 & $\ldots$ & $\ldots$ & $\ldots$ & $\ldots$ & $\ldots$ \\
IPO87019 & 0.73 & $\ldots$ & $\ldots$ & $\ldots$ & $\ldots$ \\
IPO94269 & 0.06 & -0.14 & $\ldots$ & $\ldots$ & $\ldots$ \\
ISR8036 & 0.40 & -0.09 & 0.62 & $\ldots$ & $\ldots$ \\
IPO92006 & 0.14 & -0.12 & 0.06 & -0.01 & $\ldots$ \\
\hline
\end{tabular}

distal end of the long arm of this chromosome (Fig. 5A). No QTL for resistance to ISR398 could be detected on chromosome 1D. The KK allele of Xwmc219 was approximately $185 \mathrm{bp}$ and the Shafir allele was approximately $215 \mathrm{bp}$.

Another QTL, for resistance to IPO87019, also mapped on chromosome 4A but closer to Xwmc313 (LOD = 34.15). This gene explained $80 \%$ of the phenotypic variance (Fig. $5 \mathrm{~A}$ ). There was no QTL on chromosome 1D for resistance to IPO87019. The KK allele of Xwmc313 was $195 \mathrm{bp}$ and the Shafir allele was $215 \mathrm{bp}$.

For resistance to IPO94269, a QTL for resistance to IPO94269 mapped, as expected, on chromosome 1D close to Xgwm848. The log-likelihood of the QTL was 5.17 and it explained 23\% of the phenotypic variance (Fig. 5B). No QTL for resistance to IPO94269 was detected on chromosome 4A. The KK allele of Xgwm848 was 195 bp and the Shafir allele was $201 \mathrm{bp}$.

Interval mapping of resistance to ISR8036 showed that both chromosomes 1D and 4A were of interest. QTL analysis by MQM was done first on chromosome $1 \mathrm{D}$, fitting the chromosome $4 \mathrm{~A}$ markers as cofactors, and then on chromosome 4A, fitting the chromosome 1D markers as cofactors. One QTL for resistance to ISR8036 mapped on the centromere of chromosome 1D close to Xgwm848. The log-likelihood was 7.62 and it explained $28 \%$ of

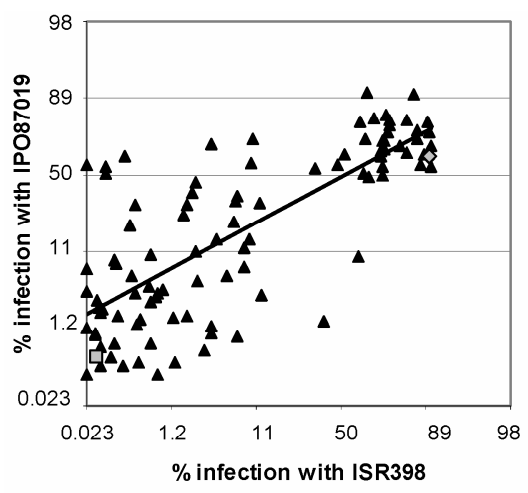

KK $\square$
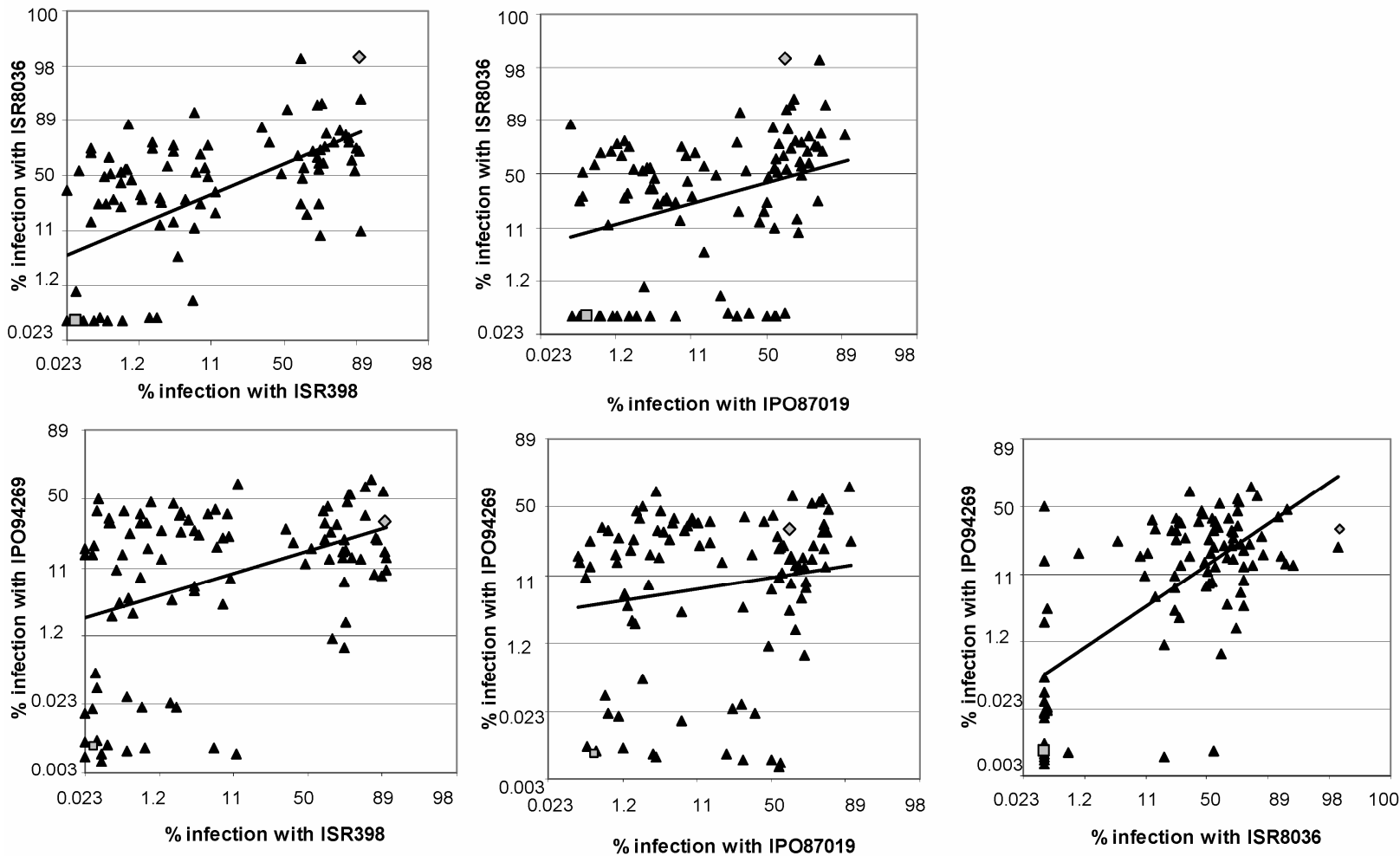

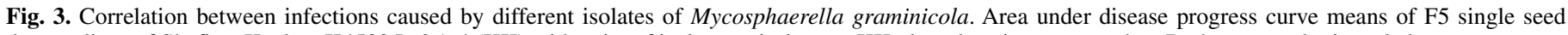
descent lines of Shafir $\times$ Kavkaz-K4500 L.6.A.4 (KK) with pairs of isolates avirulent on KK plotted against one another. Both axes are logit-scaled. 
the phenotypic variance (Fig. 5B). A second QTL with smaller effect mapped on chromosome 4A close to Xwmc219, and the log-likelihood of this QTL was 2.77 and it explained almost $9 \%$ of the phenotypic variance (Fig. 5A).

A

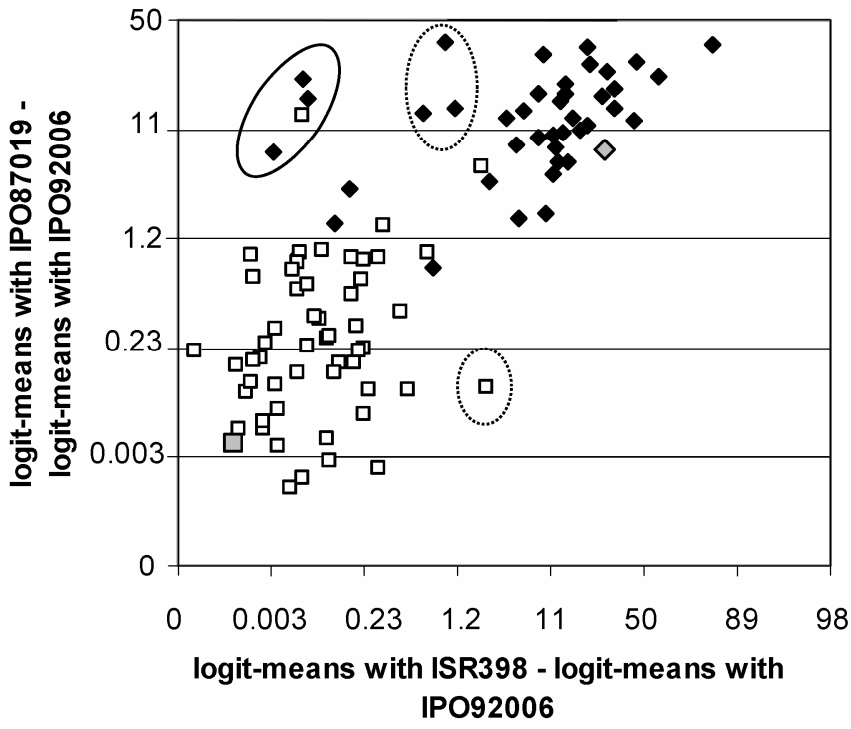

$\begin{array}{ll}\text { - Shafir allele of WMC219 } & \text { aK allele or heterozygote } \\ \diamond \text { Shafir } & \square \text { KK }\end{array}$

B

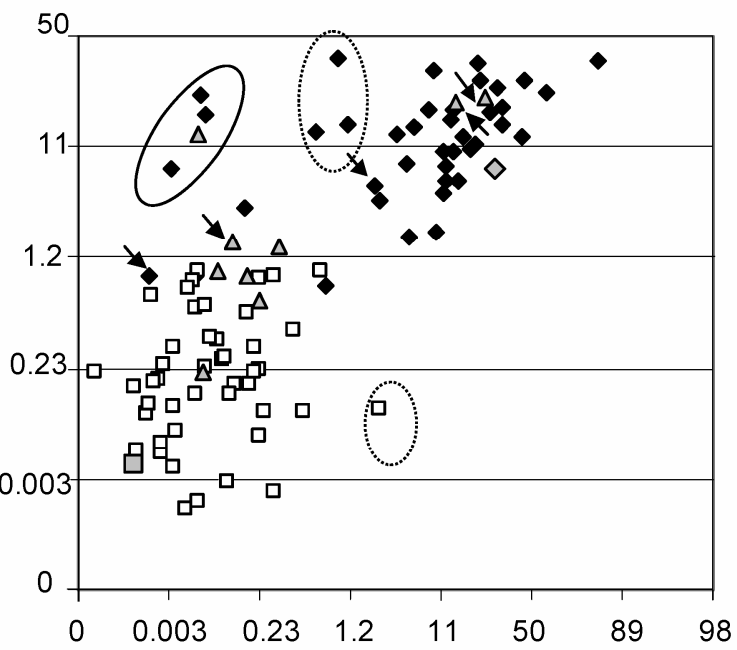

logit-means with ISR398 - logit-means with IP092006

$\begin{array}{ll}\diamond \text { Shafir allele of WMC313 } & \square \text { KK allele } \\ \Delta \text { heterozygote } & \diamond \text { Shafir } \\ \square \text { KK } & \end{array}$

Fig. 4. Segregation of the Shafir $\times$ Kavkaz-K4500 L.6.A.4 (KK) F5 single seed descent population for specific resistance to Mycosphaerella graminicola isolates. The difference between the mean logit score with ISR398 and the mean logit area under disease progress curve (AUDPC) with IPO92006 is plotted against the difference between the mean logit AUDPC with IPO87019 and the mean logit AUDPC with IPO92006. These are measures of specific resistance to ISR398 and to IPO87019, respectively. Lines are marked by their allele of A, Xwmc219; and $\mathbf{B}, X w m c 313$. The plain line circle indicates lines that are resistant to ISR398 but susceptible to IPO87019. Dotted line circle indicates lines that may be resistant to ISR398 or IPO87019 and susceptible to the other isolate. B, Points marked with an arrow indicate lines with recombination between Xwmc219 and Xwmc313. Both axes are logit-scaled.
ANOVA. ANOVA was used to confirm the isolate specificity of the genes identified. The variates analyzed were the logit mean AUDPC with each isolate. Alleles of Xwmc219, Xwmc313, or Xgwm 848 were fitted as treatment factors to test their association with responses to each isolate. For ISR398, the logit AUDPC mean from the seedling test assay was used. Xwmc219 and Xwmc313 alleles were associated with responses to ISR398, IPO87019, and ISR8036 but not to IPO92006 or IPO94269 (Table 3). Xgwm848 alleles were associated with responses to IPO94269 and ISR8036 but not to ISR398, IPO87019, or IPO92006 (Table 3).

\section{DISCUSSION}

Resistance to STB is based on a quantitative assessment of the symptoms, the expression of which varies according to the vari-
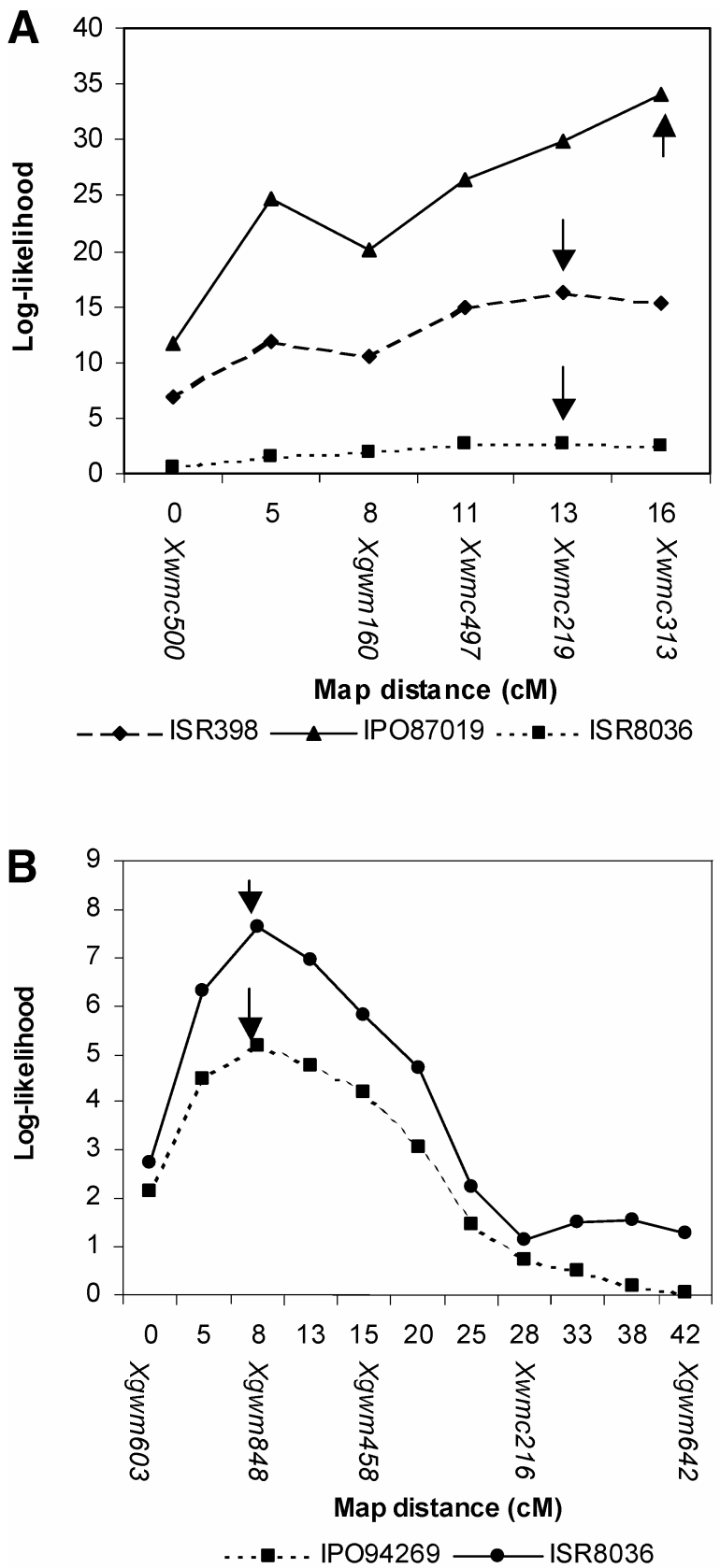

Fig. 5. A, Location of quantitative trait loci (QTL) for specific resistance to Mycosphaerella graminicola isolates IPO87019, ISR398, and IPO8036 on the distal end of chromosome 4AL. B, Location of QTL for resistance to Mycosphaerella graminicola isolates IPO94269 and ISR8036 near the centromere of chromosome 1D. The arrows indicate the position of the QTL. The log-likelihood is plotted against map distance. 
ety, the aggressiveness of the isolate, and the environmental conditions (20). For this reason, the establishment of a fixed threshold differentiating resistant from susceptible reactions is often difficult to establish. This contrasts with such diseases as powdery mildew in which there is qualitative variation between the responses of resistant and susceptible plants. In our pathology tests, the F5 SSD population of KK $\times$ Shafir segregated for resistance to ISR398, IPO87019, IPO94269, and ISR8036. For each isolate, a distinction could be made between the most resistant and the most susceptible lines, but not all the F5 lines could be classified in this way. Consequently, we used QTL analysis to study specific resistance to STB.

The gene for resistance to IPO87019 identified on chromosome 4A mapped close to the $X w m c 313$ locus. This gene may also confer resistance to ISR398 because, with the possible exception of one line, all lines resistant to IPO87019 were also resistant to ISR398 (Fig. 4). The $S t b 7$ gene was identified in the same region in the line ST6 (35). Stb7 was identified using a Canadian isolate and mapped $0.3 \mathrm{cM}$ distal from $X w m c 313$ and $0.8 \mathrm{cM}$ distal to from Xwmc219. Because the resistance gene in KK was mapped by QTL analysis, one cannot be certain that the gene identified for specific resistance to IPO87019 is indeed Stb7. Only studies on a population from a cross between KK and ST6 with both the Canadian isolate and IPO87019 could determine whether or not the two genes are the same.

A gene located close to $S t b 7$ had a major effect on resistance to ISR398 and mapped closer to the Xgwm219 locus than to Xgwm313. At least four lines were resistant to ISR398 but not to IPO87019 (Fig. 4). For these four lines, single plant scores in

TABLE 3. Analysis of variance to test the associations of three microsatellite loci (Xwmc219, Xwmc313, and Xgwm848) with responses to five isolates of Mycosphaerella graminicola in progeny lines of Shafir $\times$ Kavkaz-K4500 L.6.A.4

\begin{tabular}{lcc}
\hline Isolate & Variance ratio & $F$ test $^{\mathrm{a}}$ \\
\hline$X w m c 219$ & & \\
IPO87019 & 89.68 & $* * *$ \\
ISR398 & 35.39 & $* * *$ \\
ISR8036 & 4.17 & $* *$ \\
IPO94269 & 0.35 & $\mathrm{~ns}$ \\
IPO92006 & 1.11 & $\mathrm{~ns}$ \\
Xwmc313 & & \\
IPO87019 & 107.06 & $* * *$ \\
ISR398 & 31.14 & $* * *$ \\
ISR8036 & 2.82 & $*$ \\
IPO94269 & 0.42 & $\mathrm{~ns}$ \\
IPO92006 & 0.46 & $\mathrm{~ns}$ \\
$X g w m s 848$ & & \\
IPO87019 & 0.70 & $\mathrm{~ns}$ \\
ISR398 & 1.93 & $\mathrm{~ns}$ \\
ISR8036 & 13.86 & $* * *$ \\
IPO94269 & 10.07 & $* * *$ \\
IPO92006 & 0.85 & $\mathrm{~ns}$ \\
\hline
\end{tabular}

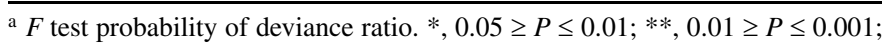
and $* * *, P \leq 0.001$. ns, not significant.

TABLE 4. Summary of the genes controlling the resistance of Kavkaz-K4500 L.6.A.4 to five isolates of Mycosphaerella graminicola

\begin{tabular}{lccc}
\hline Isolate & $\begin{array}{c}\text { Gene or genes for } \\
\text { resistance }\end{array}$ & $\begin{array}{c}\text { Chromosome } \\
\text { location }\end{array}$ & Closest marker \\
\hline IPO323 & Stb6 and $S t b x$ & $\begin{array}{c}\text { Stb6: 3A } \\
\text { StbX: unknown }\end{array}$ & Xgwm369 \\
IPO87019 & Stb7 & 4A & Xwmc313 \\
IPO94269 & Stb10 & 1D & Xgwm848 \\
ISR398 & Stb12 and possibly Stb7 & 4A & Stb7: Xgwm313 \\
& & & Stb12: Xgwm219 \\
ISR8036 & Stb10 and Stb12 & Stb10: 1D & Stb10: Xgwm848 \\
& & Stb12: 4A & Stb12: Xwmc219 \\
\hline
\end{tabular}

response to infection with each isolate were carefully checked and supported analysis based on summary statistics, which indicated that there is a gene that controls resistance to ISR398 but not IPO87019. The third PC contrasted responses to ISR398 and IPO87019 (Table 1). We conclude that there are two closely linked genes on chromosome arm 4AL between the Xgwm219 and Xgwm313 loci. The gene for resistance to ISR398 is designated here for the first time as Stb12.

These results also suggest that genes for resistance to STB may be clustered. Clusters of resistance genes have been reported many times in the literature (23), of both genes conferring resistance to different pathogens $(21,46)$ or genes conferring resistance to several genotypes of the same pathogen, like the Mla locus for resistance to powdery mildew in barley (29) or the Lr21 locus for brown rust resistance in wheat (25).

Resistance to ISR8036 was controlled by at least two genes, one mapping on chromosome $1 \mathrm{D}$ and one on $4 \mathrm{~A}$. The chromosome 4A gene mapped closer to Xwmc219 than to Xwmc313, suggesting that $S t b 12$ confers resistance to both Israeli isolates. The two genes identified here for resistance to ISR8036 on chromosomes 1D and 4A explained, in total, less than $40 \%$ of the phenotypic variance, suggesting that other genes, which we were not able to identify, may also control resistance to ISR8036.

The QTL on chromosome 1D affected the resistance to IPO94269 and ISR8036 but had no effect on IPO87019, ISR398, or IPO92006, which shows that the resistance gene at this QTL confers isolate-specific resistance. The large effect of this QTL on resistance to IPO94269 and ISR8036 and its isolate specificity suggests that it is a new gene, designated Stb10.

This study has greatly improved our knowledge about the genetics of resistance to STB in KK, one of the most important sources of resistance in wheat breeding, internationally. This line has at least five, probably six, resistance genes (Table 4). These include Stb6 on chromosome arm $3 \mathrm{AS}$ and probably a second gene for resistance to IPO323 not yet characterized (12). It has two genes on chromosome arm 4AL, one which may be $S t b 7$ and another close to $S t b 7$ which we name $S t b 12$. It also has $S t b 10$ on chromosome 1D and there may be yet another unidentified gene, which would account for part of the resistance to ISR8036. Both Stb7 and Stb10 confer resistance to several isolates of M. graminicola. These loci may therefore have value in controlling STB in wheat breeding.

Inoculation of the same F5 SSD lines with different isolates showed that Stb7, Stb10, and Stb12 are isolate-specific genes effective against more that one isolate of M. graminicola. Stb7 confers resistance in response to ISR398, IPO87019, and ISR8036 and Stb10 in response to IPO94269 and ISR8036. This suggests that ISR398 has AvrStb12 and probably AvrStb7, IPO87019 probably has AvrStb7, IPO94269 has AvrStb10, and ISR8036 has AvrStb10 and AvrStb12.

KK has resistance to STB controlled by isolate-specific genes but has little partial resistance expressed at the seedling stage (12). This suggests that pyramiding its resistance genes may be useful in breeding. It is not possible to say whether resistance to STB can be achieved by pyramiding many genes or by specific combinations of particular resistance genes. It is possible that some of the genes identified in KK have a greater contribution to field resistance than others. The Stb6 gene, for example, is in most major sources of resistance to STB, suggesting that it might contribute to field resistance $(10,12,32)$.

\section{ACKNOWLEDGMENTS}

We thank G. Kema and S. Ezrati for the gifts of the IPO isolates and ISR isolates, respectively; and the late R. Rai, Cebeco B.V., The Netherlands, and the late I. L. Groenewegen, Wiersum-Zelder B.V., The Netherlands, for the gift of the Shafir $\times$ KK F5 single seed descent lines. The research was supported by the EU Framework 4 Biotechnology Programme and by DEFRA and a consortium of six wheat breeding 
companies, Advanta Seeds UK, Cebeco Seed Innovations, Elsoms Seeds, New Farm Crops, Nickerson UK, and Semundo, through the Sustainable Arable LINK program.

\section{LITERATURE CITED}

1. Adhikari, T. B., Anderson, J. M., and Goodwin, S. B. 2003. Identification and molecular mapping of a gene in wheat conferring resistance to Mycosphaerella graminicola. Phytopathology 93:1158-1164.

2. Adhikari, T. B., Cavaletto, J. R., Dubcovsky, J., Gieco, J. O., Schlatter, A. R., and Goodwin, S. B. 2004. Molecular mappping of the Stb4 gene for resistance to Septoria tritici blotch in wheat. Phytopathology 94:1198-1206.

3. Adhikari, T. B., Young, X., Cavaletto, J. R., Hu, X., Buechley, G., Ohm, H. W., Shaner, G., and Goodwin, S. B. 2004. Molecular mappping of Stb1, a potentially durable gene for resistance to Septoria tritici blotch in wheat. Theor. Appl. Genet. 109:944-953.

4. Adhikari, T. B., Wallwork, H., and Goodwin, S. B. 2004. Microsatellite markers linked to the $S t b 2$ and $S t b 3$ genes for resistance to Septoria tritici blotch in wheat. Crop Sci. 44:1403-1411.

5. Anonymous. 2003. Strobilurin resistance in Septoria tritici in the U.K. HGCA Topic Sheet No. 69.

6. Arraiano, L. S. 2001. Genetics of resistance of wheat to septoria tritici blotch. John Innes Centre, University of East Anglia, Norwich, UK.

7. Arraiano, L. S., Brading, P. A., and Brown, J. K. M. 2001. A detached seedling leaf technique to study resistance to Mycosphaerella graminicola (anamorph Septoria tritici) in wheat. Plant Pathol. 50:339-346.

8. Arraiano, L. S., Worland, A. J., Ellerbrook, C., and Brown, J. K. M. 2001. Chromosomal location of a gene for resistance to septoria tritici blotch (Mycosphaerella graminicola) in the hexaploid wheat 'Synthetic 6x'. Theor. Appl. Genet. 103:758-764.

9. Brading, P. A., Verstappen, E. C. P., Kema, G. H. J., and Brown, J. K. M. 2002. A gene-for-gene relationship between wheat and Mycosphaerella graminicola, the Septoria tritici blotch pathogen. Phytopathology 92:439445.

10. Brown, J. K. M., Kema, G. H. J., Forrer, H. R., Verstappen, E. C. P., Arraiano, L. S., Brading, P. A., Foster, E. M., Fried, P. M., and Jenny, E. 2001. Resistance of wheat cultivars and breeding lines to septoria tritici blotch caused by isolates of Mycosphaerella graminicola in field trials. Plant Pathol. 50:325-338.

11. Chartrain, L. 2004. Genes for isolate-specific and partial resistance to septoria tritici blotch in wheat. John Innes Centre, University of East Anglia, Norwich, UK.

12. Chartrain, L., Brading, P. A., and Brown, J. K. M. 2005. Presence of the Stb6 gene for resistance to septoria tritici blotch (Mycosphaerella graminicola) in cultivars used in wheat breeding programmes worldwide. Plant Pathol. 54:134-143.

13. Chartrain, L., Brading, P. A., Makepeace, J. C., and Brown, J. K. M. 2004. Sources of resistance to septoria tritici blotch and implications for wheat breeding. Plant Pathol. 53:454-460.

14. Chartrain, L., Brading, P. A., Widdowson, J. P., and Brown, J. K. M. 2004. Partial resistance to Septoria tritici blotch (Mycosphaerella graminicola) in wheat cultivars Arina and Riband. Phytopathology 94:497-504.

15. Cohen, L., and Eyal, Z. 1993. The histology of processes associated with the Infection of resistant and susceptible wheat cultivars with Septoria tritici. Plant Pathol. 42:737-743.

16. Cowger, C., Hoffer, M. E., and Mundt, C. C. 2000. Specific adaptation by Mycosphaerella graminicola to a resistant wheat cultivar. Plant Pathol. 49:445-451.

17. Eyal, Z. 1999. The septoria tritici and stagonospora nodorum blotch diseases of wheat. Eur. J. Plant Pathol. 105:629-641.

18. Eyal, Z., and Levy, E. 1987. Variations in pathogenicity patterns of Mycosphaerella graminicola within Triticum spp. in Israel. Euphytica 36:237250.

19. Eyal, Z., Scharen, A. L., Huffman, M. D., and Prescott, J. M. 1985. Global insights into virulence frequencies of Mycosphaerella graminicola. Phytopathology 75:1456-1462.

20. Eyal, Z., and Talpaz, H. 1990. The combined effect of plant stature and maturity on the response of wheat and triticale accessions to Septoria tritici. Euphytica 46:133-141.

21. Gebhardt, C., and Valkonen, J. P. T. 2001. Organization of genes controlling disease resistance in the potato genome. Annu. Rev. Phytopathol. 39:79-102.

22. Gilchrist, L., Gomez, B., Gonzalez, R., Fuentes, S., Mujeeb-Kazi, A., Pfeiffer, W., Rajaram, S., Rodriguez, B., Skovmand, B., Van Ginkel, M., and Velazquez, C. 1999. Septoria tritici resistance sources and breeding progress at CIMMYT, 1970-99. Pages 134-139 in: Septoria and Stagonospora of Cereals. M. van Ginkel, A. McNab, and J. Krupinsky, eds. CIMMYT, Mexico.
23. Hammond-Kosack, K. E., and Jones, J. D. G. 1997. Plant disease resistance genes. Annu. Rev. Plant Physiol. Plant Mol. Biol. 48:575-607.

24. Hardwick, N. V., Jones, D. R., and Slough, J. E. 2001. Factors affecting diseases of winter wheat in England and Wales, 1989-98. Plant Pathol. 50:453-462.

25. Huang, L., and Gill, B. S. 2001. An RGA-like marker detects all known Lr21 leaf rust resistance gene family members in Aegilops tauschii and wheat. Theor. Appl. Genet. 103:1007-1013.

26. Jansen, R. C. 1993. Interval mapping of multiple quantitative trait loci. Genetics 135:205-211.

27. Jansen, R. C., and Stam, P. 1994. High-resolution of quantitative traits into multiple loci via interval mapping. Genetics 136:1447-1455.

28. Jlibene, M., Gustafson, J. P., and Rajaram, S. 1994. Inheritance of resistance to Mycosphaerella graminicola in hexaploid wheat. Plant Breed. 112:301-310.

29. Jorgensen, J. H. 1992. Multigene families of powdery mildew resistance genes in locus Mla on barley chromosome 5. Plant Breed. 108:53-59.

30. Kema, G. H. J., Annone, J. G., Sayoud, R., van Silfhout, C. H., van Ginkel, M., and deBree, J. 1996. Genetic variation for virulence and resistance in the wheat-Mycosphaerella graminicola pathosystem. I. Interactions between pathogen isolates and host cultivars. Phytopathology $86: 200-212$

31. Kema, G. H. J., Sayoud, R., Annone, J. G., and van Silfhout, C. H. 1996. Genetic variation for virulence and resistance in the wheat-Mycosphaerella graminicola pathosystem. II. Analysis of interactions between pathogen isolates and host cultivars. Phytopathology 86:213-220.

32. Kema, G. H. J., and van Silfhout, C. H. 1997. Genetic variation for virulence and resistance in the wheat-Mycosphaerella graminicola pathosystem. III. Comparative seedling and adult plant experiments. Phytopathology 87:266-272.

33. Kema, G. H. J., Verstappen, E. C. P., and Waalwijk, G. 2000. Avirulence in the wheat Septoria tritici leaf blotch fungus Mycosphaerella graminicola is controlled by a single locus. Mol. Plant-Microbe Interact. 13:1375-1379.

34. Kosambi, D. D. 1944. The estimation of map distances from recombination values. Ann. Eugen. 12:172-175.

35. McCartney, C. A., Brûlé-Babel, A. L., and Lamari, L. 2002. Inheritance of race-specific resistance to Mycosphaerella graminicola in wheat. Phytopathology 92:138-144.

36. Michelmore, R. W., Paran, I., and Kesseli, R. V. 1994. Identification of markers linked to disease-resistance genes by bulked segregant analysis: A rapid method to detect markers in specific genomic regions by using segregating populations. Proc. Natl. Acad. Sci. USA 88:98289832.

37. Payne, R. 2000. The Guide to Genstat. Lawes Agricultural Trust, Harpenden, UK.

38. Pestsova, E., Ganal, M. W., and Roder, M. S. 2000. Isolation and mapping of microsatellite markers specific for the D genome of bread wheat. Genome 43:689-697.

39. Polley, R. W., and Thomas, M. R. 1991. Surveys of diseases of winter wheat in England and Wales, 1976-1988. Ann. Appl. Biol. 119:1-20.

40. Röder, M. S., Korzun, V., Wendehake, K., Plaschke, J., Tixier, M. H., Leroy, P., and Ganal, M. W. 1998. A microsatellite map of wheat. Genetics 149:2007-2023.

41. Shaner, G., and Finney, R. 1977. The effect of nitrogen fertilization on the expression of slow mildewing resistance in Knox wheat. Phytopathology 67:1051-1056

42. Simon, M. R., and Cordo, C. A. 1998. Diallel analysis of four resistance components to Septoria tritici in six crosses of wheat (Triticum aestivum). Plant Breed. 117:123-126.

43. Stam, P., and van Ooijen, J. W. 1995. JoinMap version 2.0: Software for the calculation of genetic linkage maps. Plant Research International, Wageningen, The Netherlands.

44. van Ginkel, M., and Rajaram, S. 1993. Breeding for durable resistance to diseases in wheat: An international perspective. Pages 258-279 in: Durability of Disease Resistance. T. Jacobs and J. E. Parlevliet, eds. Kluwer Academic Publishers, Dordrecht, The Netherlands.

45. van Ooijen, J. W., and Maliepaard, C. 1996. MapQTL version 3.0: Software for the calculation of QTL positions on genetics maps. Plant Research International, Wageningen, The Netherlands.

46. Witsenboer, H., Kesseli, R. V., Fortin, M. G., Stanghellini, M., and Michelmore, R. W. 1995. Sources and genetic-structure of a cluster of genes for resistance to 3 pathogens in lettuce. Theor. Appl. Genet. 91:178188.

47. Zelikovitch, N., and Eyal, Z. 1989. Maintenance of virulence of Septoria tritici cultures. Mycol. Res. 92:361-364.

48. Zhang, X., Haley, S. D., and Jin, Y. 2001. Inheritance of septoria tritici blotch resistance in winter wheat. Crop Sci. 41:323-326. 